\title{
Knowledge, attitude, and perception of oral and maxillofacial surgery specialty amongst healthcare professionals, and the General Public from a Gulf Cooperation Council (GCC) Country
}

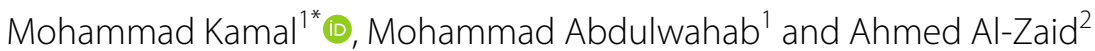

\begin{abstract}
Background: Oral and maxillofacial surgery specialty has grown rapidly in Kuwait in recent years. However, the general public and healthcare professionals remain unaware of its expanding scope of practice. The aim of the study is to assess public and professional (dental and medical) perception of the oral and maxillofacial surgical specialty in Kuwait.

Methods: This is a cross-sectional study evaluating responses of dental professionals, medical professionals, and general public in Kuwait toward the oral and maxillofacial surgical specialty using a previously validated survey instrument with 100 participants in each group. Participants were asked to choose the most appropriate specialist to treat certain procedures across 4 disciplines: reconstruction, trauma, pathology, and cosmetic. Statistical comparison was conducted between dentists and medical doctors using Fisher's exact test with a p-value of $<0.05$.

Results: Disparities were noted each group's responses. Oral and maxillofacial surgery was preferred overall for most clinical scenarios in trauma $(p<0.001)$, pathology $(p<0.001)$, and reconstructive surgery $(p<0.001)$. Plastic surgery was preferred for cosmetic surgeries $(p<0.001)$.

Conclusions: This study indicates the need to increase awareness especially towards cosmetic surgery procedures, and conduct health campaigns regarding oral and maxillofacial surgery among healthcare professionals, especially medical doctors, and the general public.
\end{abstract}

Keywords: Perception, Awareness, Oral and maxillofacial surgery, Specialty

\section{Background}

Oral and maxillofacial surgery (OMFS) is a relatively young surgical specialty that focuses on diagnosing and treating conditions in the head and neck region, acting as a bridge between dentistry and medicine $[1,2]$. OMFS

\footnotetext{
*Correspondence: mohammad.kamal@ku.edu.kw

${ }^{1}$ Department of Surgical Sciences, Faculty of Dentistry, Health Sciences Center, Kuwait University, Safat, Kuwait

Full list of author information is available at the end of the article
}

evolved significantly in recent years, triggering major technological and clinical advances in the fields of traumatology, dentofacial deformities, head and neck oncology and reconstruction, and temporomandibular joint disorders [3, 4]. Presently, OMFS offers a fairly broad spectrum of treatments, including distraction osteogenesis, implant surgery, tissue engineering, sleep apnea treatment, and esthetic facial surgery $[3,5,6]$.

Despite being a well-recognized specialty of the facial skeleton by major hospitals internationally, 
disparities remain regarding proper recognition of OMFS's scope and familiarity with OMFS surgical procedures among students, healthcare professionals, and laypersons [2, 4, 5]. Previous work in Kuwait by Haron et al. assessed the perception of OMFS by medical and dental professionals and found disparity regarding healthcare professional consultations for various conditions in the head and neck region based on a survey instrument evaluating 26 procedures [7]. A similar study in Saudi Arabia by Alnofaie et al. showed also significant differences between dentists and medical doctors perceiving OMFS [8].

The practice of OMFS in Kuwait officially began in the 1960s, mostly by foreign specialists visiting or practicing on regular basis. During later years, the development of the Kuwait healthcare and educational system led to local doctors being trained abroad in several North-American, European, Asian, and NorthAfrican countries to prepare them for the nationally subsidized Kuwaiti healthcare sector [7]. Over time, a heterogeneous group of OMFS surgeons formed with diverse training and a spectrum of clinical practice. The medical system in Kuwait is based on providing comprehensive care by the state-funded hospitals and many health care primary centers. Five health regions, with over 70 primary healthcare centers are responsible for managing the whole population in the state of Kuwait [9]. Primary healthcare centers are well staffed with general practitioners and general dentists who licensed thorough the Ministry of Health to offer mainly primary healthcare needs and serve as the initiating pathway toward referring cases to specialized centers for secondary and tertiary care services. The services provided across this multilateral system covers the whole spectrum of all medical and surgical specialties, along with the full spectrum of dental specialties. The Kuwait Ministry of Health attempts evaluate the standard of care, accreditation protocols, and the referral guidelines across all centers on regular basis [9]. There is currently insufficient reports on topics evaluating the medical referral system in Kuwait, with few studies published focusing mostly on patient safety culture and medical errors in the State of Kuwait $[10,11]$.

We shall investigate the current levels of knowledge, attitude, and perception towards the OMFS specialty in Kuwait among dental and medical professionals as well as the general public. This will help revisit our referral protocols, conduct needed awareness campaigns among the healthcare professionals to enhance their understanding of the scope of the specialty, and refine our medical and dental school's curriculum to increase the OMFS educational content.

\section{Methods}

\section{Participants}

This cross-sectional survey drew one hundred subjects $(n=100)$ from both registered dentists and medical doctors working in all Kuwaiti healthcare sectors, the governmental and the private sectors, as well as the general public (laypersons) between April 1st to May 30th 2020. Participants were at least 18 years old and all participants voluntarily gave written consent to complete the questionnaire and were assured that their responses would be anonymous.

\section{Questionnaire}

A previously validated and applied survey is used in the study with slight modifications by expanding the procedures list, and permission to use the questionnaire has been obtained from its authors $[12,13]$. The questionnaire is divided into sections on demographics and general head and neck clinical conditions, some specific to OMFS practice (see Additional files, Questionnaire OMFS.pdf). Additional items are included in the survey to expand the spectrum and give a broader range of clinical scenarios. Each participant has 5 options consisting of 4 different specialists and an unspecified specialty. Participants are asked to indicate whom would be most appropriate or competent in treating each clinical condition, and only one option can be chosen for each condition. The questions are grouped and categorized by discipline (trauma, pathology, reconstruction, or cosmetic) and analyzed accordingly. Links leading to the online survey instrument was electronically to the medical and dental associations groups and to the public groups in Kuwait via e-mail, WhatsApp, Instagram, and Twitter pages. Ethical approval was obtained for this study from the Institutional Review Board (IRB) at Kuwait University Health Sciences Center.

\section{Statistical analysis}

Statistical analysis is performed using SPSS Version 23.0 (IBM SPSS Statistics for Macintosh, IBM Corp., Armonk, NY, USA). Questionnaire responses from dentists and medical doctors are compared. Categorical data is compared using a chi-square test (cell count $\geq 5$ ) or Fisher's exact test (cell counts $<5$ ). A p-value of $<0.05$ is considered statistically significant given an $80 \%$ test power. Responses by laypeople are presented categorically and not included in the statistical comparison.

\section{Results}

Healthcare professionals (dentists and physicians)

The participants who completed the questionnaire consisted of 100 dentists and 100 physicians (Table 1). Participants were male (58\%) and female $(42 \%)$, with the 
Table 1 Respondent characteristics: number of participants, gender, age range, and years of experience

\begin{tabular}{|c|c|c|c|c|c|c|c|c|c|}
\hline & Nr. participants & Gend & & Age rar & -years & & & & Years of experience \\
\hline & $\mathrm{n}=\%$ & Male & Female & $18-25$ & $26-35$ & $36-45$ & $46-55$ & $>55$ & \\
\hline Dentists & 100 & 62 & 38 & 17 & 52 & 22 & 9 & 0 & $7.9( \pm 7.4)$ \\
\hline Medical doctors & 100 & 54 & 46 & 6 & 43 & 37 & 14 & 0 & $10.1( \pm 6.9)$ \\
\hline General public & 100 & 55 & 45 & 9 & 32 & 22 & 22 & 15 & - \\
\hline Total & 300 & 171 & 129 & 32 & 127 & 81 & 45 & 15 & \\
\hline
\end{tabular}

As each group contained 100 participants, cell values represent both $\mathrm{n}$ and $\%$

majority aged 26-45 years. Medical doctors were older than their dentist counterparts $(p=0.012)$ and had more clinical experience $(\mathrm{p}=0.033)$ with dentists possessing an average of 7.9 years ( $\mathrm{SD} \pm 7.4$ years) compared to doctors holding 10.1 years ( $\mathrm{SD} \pm 6.9$ years). Regarding receiving care, $27 \%$ had been supported by ear-nose-throat (ENT) specialists and $23 \%$ were treated by OMFS specialists, while $41 \%$ reported no prior medical treatment. Medical doctors had more personal experience with plastic surgery (PS) and ENT specialists while dentists had more personal experience with OMFS $(\mathrm{p}<0.001)$.

Responses to trauma-related questions relating are presented in Table 2. An OMFS was preferred by both groups to treat broken jaws, eye bone fractures, and teeth trauma. Both groups would refer to PS for facial lacerations, but a larger proportion of dentists would refer to OMFS ( $43 \%$ vs. $19 \%$; $\mathrm{p}<0.001)$ while a larger proportion of medical doctors would refer to general surgery (GS) $(26 \%$ vs. $7 \%$; $\mathrm{p}<0.001)$. Nose fractures caused more doctors to refer to ENT ( $79 \%$ vs. $43 \%$; $p<0.001)$ while significantly more dentists would include an OMFS referral ( $37 \%$ vs. $4 \%$; $<<0.001$ ).

Table 3 presents responses relating to pathology, showing OMFS being preferred by both groups for oral lesion biopsies, cancers of the lip, mouth, or tongue, and mouth lumps. For facial skin lesion biopsies, dentists tended to refer to OMFS ( $53 \%$ vs. $19 \%$; $<<0.001$ ), while doctors preferred PS $(51 \%$ vs. $29 \%$; $<<0.001)$. A patient seeking removal of a neck lump would be unlikely to get an OMFS referral from a medical doctor $(7 \%$ vs. $63 \%$;

Table 2 Trauma

\begin{tabular}{|c|c|c|c|c|c|c|}
\hline Condition & Role & Plastic surgeon & Ear-nose-throat & $\begin{array}{l}\text { Oral } \\
\text { and maxillofacial } \\
\text { surgeon }\end{array}$ & General surgeon & Others \\
\hline \multirow[t]{3}{*}{ Broken jaw } & Dentist & 1 & 0 & 99 & 0 & 0 \\
\hline & Medical Doctor & 0 & 0 & 100 & 0 & 0 \\
\hline & $p$ & 1.000 & - & 1.000 & - & - \\
\hline \multirow[t]{3}{*}{ Cut on the face (Laceration) } & Dentist & 50 & 0 & 43 & 7 & 0 \\
\hline & Medical doctor & 45 & 0 & 19 & 26 & 10 \\
\hline & $p$ & 0.479 & - & $<0.001$ & $<0.001$ & 0.002 \\
\hline \multirow[t]{3}{*}{ Eye bone fracture (orbit) } & Dentist & 8 & 4 & 83 & 5 & 0 \\
\hline & Medical doctor & 3 & 12 & 67 & 3 & 15 \\
\hline & $p$ & 0.213 & 0.065 & 0.009 & 0.721 & $<0.001$ \\
\hline \multirow[t]{3}{*}{ Fracture of the skull } & Dentist & 7 & 1 & 68 & 19 & 5 \\
\hline & Medical doctor & 3 & 25 & 23 & 10 & 39 \\
\hline & $p$ & 0.331 & $<0.001$ & $<0.001$ & 0.071 & $<0.001$ \\
\hline \multirow[t]{3}{*}{ Nose fracture } & Dentist & 20 & 42 & 37 & 1 & 0 \\
\hline & Medical doctor & 17 & 79 & 4 & 0 & 0 \\
\hline & $p$ & 0.585 & $<0.001$ & $<0.001$ & 1.000 & - \\
\hline \multirow[t]{3}{*}{ Trauma to the teeth } & Dentist & 1 & 1 & 72 & 5 & 21 \\
\hline & Medical doctor & 0 & 0 & 75 & 0 & 25 \\
\hline & $p$ & 1.000 & 1.000 & 0.631 & 0.059 & 0.502 \\
\hline
\end{tabular}

As each group contained 100 participants, cell values represent both $n$ and $\%$

Column $p$ values were generated from a Chi-square test (cell count $\geq 5$ ) or a Fisher's exact test (cell count $<5$ ) 
Table 3 Pathology

\begin{tabular}{|c|c|c|c|c|c|c|}
\hline Condition & Role & Plastic surgeon & ear-nose-throat & $\begin{array}{l}\text { Oral } \\
\text { and maxillofacial } \\
\text { surgeon }\end{array}$ & General surgeon & Others \\
\hline \multirow[t]{3}{*}{ Biopsy of a skin lesion on the face } & Dentist & 29 & 0 & 53 & 13 & 5 \\
\hline & Medical doctor & 51 & 3 & 19 & 13 & 14 \\
\hline & $p$ & 0.001 & 0.246 & $<0.001$ & 1.000 & 0.030 \\
\hline \multirow[t]{3}{*}{ Biopsy of oral lesions } & Dentist & 2 & 1 & 87 & 8 & 2 \\
\hline & Medical doctor & 3 & 11 & 80 & 3 & 3 \\
\hline & $p$ & 1.000 & 0.005 & 0.182 & 0.213 & 1.000 \\
\hline \multirow[t]{3}{*}{ Cancer of the lip } & Dentist & 10 & 2 & 87 & 1 & 0 \\
\hline & Medical doctor & 28 & 11 & 55 & 3 & 3 \\
\hline & $p$ & 0.001 & 0.018 & $<0.001$ & 0.621 & 0.246 \\
\hline \multirow[t]{3}{*}{ Cancer of the mouth or tongue } & Dentist & 1 & 1 & 97 & 0 & 1 \\
\hline & Medical doctor & 0 & 16 & 84 & 0 & 0 \\
\hline & $p$ & 1.000 & $<0.001$ & 0.003 & - & 1.000 \\
\hline \multirow[t]{3}{*}{ Lump in the mouth } & Dentist & 2 & 1 & 94 & 3 & 0 \\
\hline & Medical doctor & 0 & 16 & 81 & 3 & 0 \\
\hline & $p$ & 0.497 & $<0.001$ & 0.005 & 1.000 & - \\
\hline \multirow[t]{3}{*}{ Lump in the neck } & Dentist & 4 & 13 & 63 & 19 & 1 \\
\hline & Medical doctor & 3 & 53 & 7 & 37 & 0 \\
\hline & $p$ & 1.000 & $<0.001$ & $<0.001$ & 0.005 & 1.000 \\
\hline \multirow[t]{3}{*}{ Mole or lump in the face (Skin) } & Dentist & 41 & 1 & 39 & 13 & 6 \\
\hline & Medical doctor & 53 & 0 & 18 & 12 & 17 \\
\hline & $p$ & 0.089 & 1.000 & 0.001 & 0.831 & 0.015 \\
\hline \multirow{3}{*}{$\begin{array}{l}\text { Salivary gland removal (Parotid, } \\
\text { Submandibular) }\end{array}$} & Dentist & 1 & 6 & 90 & 3 & 0 \\
\hline & Medical doctor & 2 & 52 & 31 & 15 & 0 \\
\hline & $p$ & 1.000 & $<0.001$ & $<0.001$ & 0.003 & - \\
\hline \multirow[t]{3}{*}{ Sinus surgery } & Dentist & 2 & 40 & 51 & 2 & 5 \\
\hline & Medical doctor & 0 & 80 & 7 & 13 & 0 \\
\hline & $p$ & 0.497 & $<0.001$ & $<0.001$ & 0.005 & 0.059 \\
\hline
\end{tabular}

As each group contained 100 participants, cell values represent both $\mathrm{n}$ and $\%$

Column $p$ values were generated from a Chi-square test (cell count $\geq 5$ ) or Fisher's exact test (cell count $<5$ )

$\mathrm{p}<0.001)$, who generally preferred ENT $(53 \% ; \mathrm{p}<0.001)$ or GS referrals (37\%; $\mathrm{p}=0.003)$. For salivary gland removal and sinus surgery, medical doctors preferred ENT $(52 \%$ and $80 \% ; \mathrm{p}<0.001)$ while dentists preferred OMFS for both procedures $(90 \%$ and $51 \%$; $\mathrm{p}<0.001)$.

PS or OMFS was preferred for reconstructive surgery scenarios (Table 4). Dentists preferred OMFS for children with cleft lips $(p<0.001)$, cleft palates $(p<0.001)$, and both conditions $(\mathrm{p}<0.001)$, while medical doctors referred to PS most often for these procedures. Facial reconstruction following trauma saw dentists more likely to choose OMFS (69\% vs. $48 \% ; \mathrm{p}=0.003)$ and medical doctors preferring PS $(52 \%$ vs. $30 \%$; $p=0.002)$. Dentists referred to PS (46\%) and OMFS (47\%) in roughly equal numbers for facial reconstruction requiring free flaps but medical doctors were more likely to refer to PS (72\%; $\mathrm{p}<0.001)$ than OMFS $(28 \% ; \mathrm{p}=0.006)$. Similarly, dentists would refer to OMFS for facial bone grafts more than medical doctors ( $75 \%$ vs. $44 \%$; $\mathrm{p}<0.001)$. While both dentists and medical doctors would refer to OMFS for wisdom teeth removal, a large proportion of doctors would also refer to other specialties $(34 \% ; \mathrm{p}<0.001)$.

PS was preferred for all cosmetic surgeries save chin corrections, jaw deformities and discrepancies, and rhinoplasty (Table 5). OMFS was preferred for chin correction surgery by dentists more than medical doctors $(73 \%$ vs. $56 \% ; \mathrm{p}=0.012$ ) and approximately equally for jaw deformities and discrepancies $(93 \%$ and $92 \% ; p=0.788)$. For rhinoplasty, dentists had a stronger preference for PS $(60 \%$ vs. $38 \% ; \mathrm{p}=0.002)$ and medical doctors preferred ENT specialists $(53 \% ; \mathrm{p}=0.010)$.

Figure 1 illustrates that OMFS was preferred overall by dentists and medical doctors for most clinical scenarios in trauma $(\mathrm{p}<0.001)$, pathology $(\mathrm{p}<0.001)$, and reconstructive surgery $(\mathrm{p}<0.001)$. PS was preferred for cosmetic surgeries $(\mathrm{p}<0.001)$. 
Table 4 Reconstructive surgery

\begin{tabular}{|c|c|c|c|c|c|c|}
\hline Condition & Role & Plastic surgeon & Ear-nose-throat & $\begin{array}{l}\text { Oral } \\
\text { and maxillofacial } \\
\text { surgeon }\end{array}$ & General surgeon & Others \\
\hline \multirow[t]{3}{*}{ Child with a cleft lip } & Dentist & 25 & 0 & 72 & 1 & 2 \\
\hline & Medical doctor & 61 & 8 & 31 & 0 & 0 \\
\hline & $p$ & $<0.001$ & 0.007 & $<0.001$ & 1.000 & 0.497 \\
\hline \multirow[t]{3}{*}{ Child with a cleft palate } & Dentist & 5 & 2 & 88 & 2 & 3 \\
\hline & Medical doctor & 51 & 15 & 30 & 0 & 4 \\
\hline & $p$ & $<0.001$ & 0.002 & $<0.001$ & 0.497 & 1.000 \\
\hline \multirow{3}{*}{ Child with a cleft lip + palate } & Dentist & 7 & 3 & 86 & 1 & 3 \\
\hline & Medical doctor & 60 & 9 & 31 & 0 & 0 \\
\hline & $p$ & $<0.001$ & 0.134 & $<0.001$ & 1.000 & 0.246 \\
\hline \multirow[t]{3}{*}{ Dental implants } & Dentist & 1 & 1 & 77 & 5 & 16 \\
\hline & Medical doctor & 0 & 0 & 80 & 0 & 20 \\
\hline & $p$ & 1.000 & 1.000 & 0.606 & 0.059 & 0.462 \\
\hline \multirow[t]{3}{*}{ Facial reconstruction after facial trauma } & Dentist & 30 & 0 & 69 & 0 & 1 \\
\hline & Medical doctor & 52 & 0 & 48 & 0 & 0 \\
\hline & $p$ & 0.002 & - & 0.003 & - & 1.000 \\
\hline \multirow[t]{3}{*}{ Facial reconstruction with free flaps } & Dentist & 46 & 3 & 47 & 2 & 2 \\
\hline & Medical doctor & 72 & 0 & 28 & 0 & 0 \\
\hline & $p$ & $<0.001$ & 0.246 & 0.006 & 0.497 & 0.497 \\
\hline \multirow[t]{3}{*}{ Grafting bone in the face } & Dentist & 21 & 1 & 75 & 2 & 1 \\
\hline & Medical doctor & 50 & 3 & 44 & 3 & 0 \\
\hline & $p$ & $<0.001$ & 0.621 & $<0.001$ & 1.000 & 1.000 \\
\hline \multirow[t]{3}{*}{ Removal of wisdom teeth } & Dentist & 1 & 1 & 87 & 5 & 6 \\
\hline & Medical doctor & 0 & 0 & 66 & 0 & 34 \\
\hline & $p$ & 1.000 & 1.000 & $<0.001$ & 0.059 & $<0.001$ \\
\hline \multirow[t]{3}{*}{ Temporomandibular joint (TMJ) surgery } & Dentist & 1 & 3 & 95 & 1 & 0 \\
\hline & Medical doctor & 0 & 10 & 90 & 0 & 0 \\
\hline & $p$ & 1.000 & 0.082 & 0.179 & 1.000 & - \\
\hline \multirow{3}{*}{$\begin{array}{l}\text { Taking bone from rib/hip for intra-oral graft- } \\
\text { ing }\end{array}$} & Dentist & 11 & 0 & 67 & 19 & 3 \\
\hline & Medical doctor & 30 & 3 & 51 & 10 & 6 \\
\hline & $p$ & 0.001 & 0.246 & 0.021 & 0.071 & 0.498 \\
\hline
\end{tabular}

As each group contained 100 participants, cell values represent both $\mathrm{n}$ and $\%$

Column $\mathrm{p}$ values were generated from a Chi-square test (cell count $\geq 5$ ) or a Fisher's exact test (cell count $<5$ )

\section{Laypeople}

One hundred laypeople were surveyed as part of this study (see Table 6), comprising 55 males and an even distribution of age ranges. Survey respondents reported their personal experiences with various specialties, with $12 \%$ having received PS treatment, $27 \%$ receiving ENT, $24 \%$ using OMFS, $77 \%$ accepting GS, and $26 \%$ getting another form of treatment.

Overall, OMFS was preferred for issues relating to trauma, pathology, and reconstructive surgery, while PS was preferred for cosmetic surgeries (Fig. 2). Laypeople felt that ENT services were most appropriate for nose fractures and sinus surgeries. They choose PS as most appropriate for facial lacerations, moles/lumps on the face, cleft lips, facial reconstructions and all cosmetic surgeries except jaw deformities and discrepancies. GS was deemed most appropriate for facial skin lesion biopsies and neck lumps. Perception of when OMFS consultation was suitable is presented in Table 7.

\section{Discussion}

Knowledge and perception of the OMFS specialty plays a crucial role in its development. With its wide scope of practice overlapping other medical specialties, OMFS has caused a notable disparity in referring preferences among healthcare workers, students, and general public $[8,12]$. Jensen mentioned that almost all medical specialties have overlapping scope to some extent, causing possible 
Table 5 Cosmetic surgery

\begin{tabular}{|c|c|c|c|c|c|c|}
\hline Condition & Role & Plastic surgeon & Ear-nose-throat & $\begin{array}{l}\text { Oral } \\
\text { and maxillofacial } \\
\text { surgeon }\end{array}$ & General surgeon & Others \\
\hline \multirow[t]{3}{*}{ Chin correction surgery } & Dentist & 23 & 3 & 73 & 0 & 1 \\
\hline & Medical doctor & 41 & 3 & 56 & 0 & 0 \\
\hline & $p$ & 0.006 & 1.000 & 0.012 & - & 1.000 \\
\hline \multirow[t]{3}{*}{ Eyelid Surgery (Blepharoplasty) } & Dentist & 57 & 3 & 28 & 8 & 4 \\
\hline & Medical Doctor & 58 & 14 & 4 & 0 & 24 \\
\hline & $p$ & 1.000 & 0.009 & $<0.001$ & 0.007 & $<0.001$ \\
\hline \multirow[t]{3}{*}{ Face lift } & Dentist & 72 & 0 & 24 & 3 & 1 \\
\hline & Medical doctor & 82 & 9 & 9 & 0 & 0 \\
\hline & $p$ & 0.093 & 0.003 & 0.004 & 0.246 & 1.000 \\
\hline \multirow[t]{3}{*}{ Facial implants (silicone or other alloplasts) } & Dentist & 62 & 1 & 36 & 0 & 1 \\
\hline & Medical doctor & 77 & 2 & 21 & 0 & 0 \\
\hline & $p$ & 0.021 & 1.000 & 0.019 & - & 1.000 \\
\hline \multirow[t]{3}{*}{ Fat grafting to the face } & Dentist & 73 & 0 & 19 & 5 & 3 \\
\hline & Medical doctor & 79 & 9 & 12 & 0 & 0 \\
\hline & $p$ & 0.321 & 0.003 & 0.171 & 0.059 & 0.246 \\
\hline \multirow[t]{3}{*}{ Hair transplant } & Dentist & 65 & 1 & 3 & 4 & 27 \\
\hline & Medical doctor & 59 & 9 & 0 & 3 & 29 \\
\hline & $p$ & 0.382 & 0.018 & 0.246 & 1.000 & 0.753 \\
\hline \multirow[t]{3}{*}{ Injection of Botox and fillers } & Dentist & 71 & 3 & 11 & 4 & 11 \\
\hline & Medical doctor & 76 & 12 & 0 & 0 & 12 \\
\hline & $p$ & 0.423 & 0.029 & 0.001 & 0.121 & 1.000 \\
\hline \multirow[t]{3}{*}{ Jaw deformities and discrepancy } & Dentist & 6 & 1 & 93 & 0 & 0 \\
\hline & Medical doctor & 8 & 0 & 92 & 0 & 0 \\
\hline & $p$ & 0.579 & 1.000 & 0.788 & - & - \\
\hline \multirow[t]{3}{*}{ Laser resurfacing of facial skin } & Dentist & 80 & 0 & 6 & 1 & 13 \\
\hline & Medical doctor & 75 & 9 & 2 & 0 & 14 \\
\hline & $p$ & 0.397 & 0.003 & 0.279 & 1.000 & 1.000 \\
\hline \multirow{3}{*}{$\begin{array}{l}\text { Problem with facial appearance or asym- } \\
\text { metry }\end{array}$} & Dentist & 54 & 1 & 44 & 1 & 0 \\
\hline & Medical doctor & 51 & 3 & 43 & 0 & 3 \\
\hline & $p$ & 0.671 & 0.621 & 0.887 & 1.000 & 0.246 \\
\hline \multirow[t]{3}{*}{ Rhinoplasty (Nose plastic surgery) } & Dentist & 60 & 35 & 4 & 1 & 0 \\
\hline & Medical doctor & 38 & 53 & 9 & 0 & 0 \\
\hline & $p$ & 0.002 & 0.010 & 0.251 & 1.000 & - \\
\hline
\end{tabular}

As each group contained 100 participants, cell values represent both $\mathrm{n}$ and $\%$

Column $p$ values were generated from a Chi-square test (cell count $\geq 5$ ) or a Fisher's exact test (cell count $<5$ )

confusion when choosing an appropriate specialty for case management [14]. This necessitates establishing clear clinical guidelines and interdepartmental referral schemes in any given healthcare system. Proper referral systems ultimately lead to better patient care delivery, smaller burdens on hospital services, and greater patient satisfaction $[15,16]$. Undoubtedly, OMFS surgeons will most likely continue to gather knowledge and clinical skills depending on case exposure to over time.

General public perception of OMFS is just as important health care provider perception. In Kuwait's private sector, the public has open access to all specialty clinics. Although such unrestricted access has benefits (such as fast patient flow), they are countered by possibly inappropriate self-referrals [16]. The latter causes higher patient costs in addition to increased risk of management by health care providers not entirely skilled in a given case [16]. Our findings indicate that most medical and dental clinicians will refer to OMFS for jaw fractures, orbital fractures, and dental trauma instead of ENT, GS, or PS, which is consistent with Rocha et al's findings [13]. The orbital fracture findings contradict Haron et al's 2013 


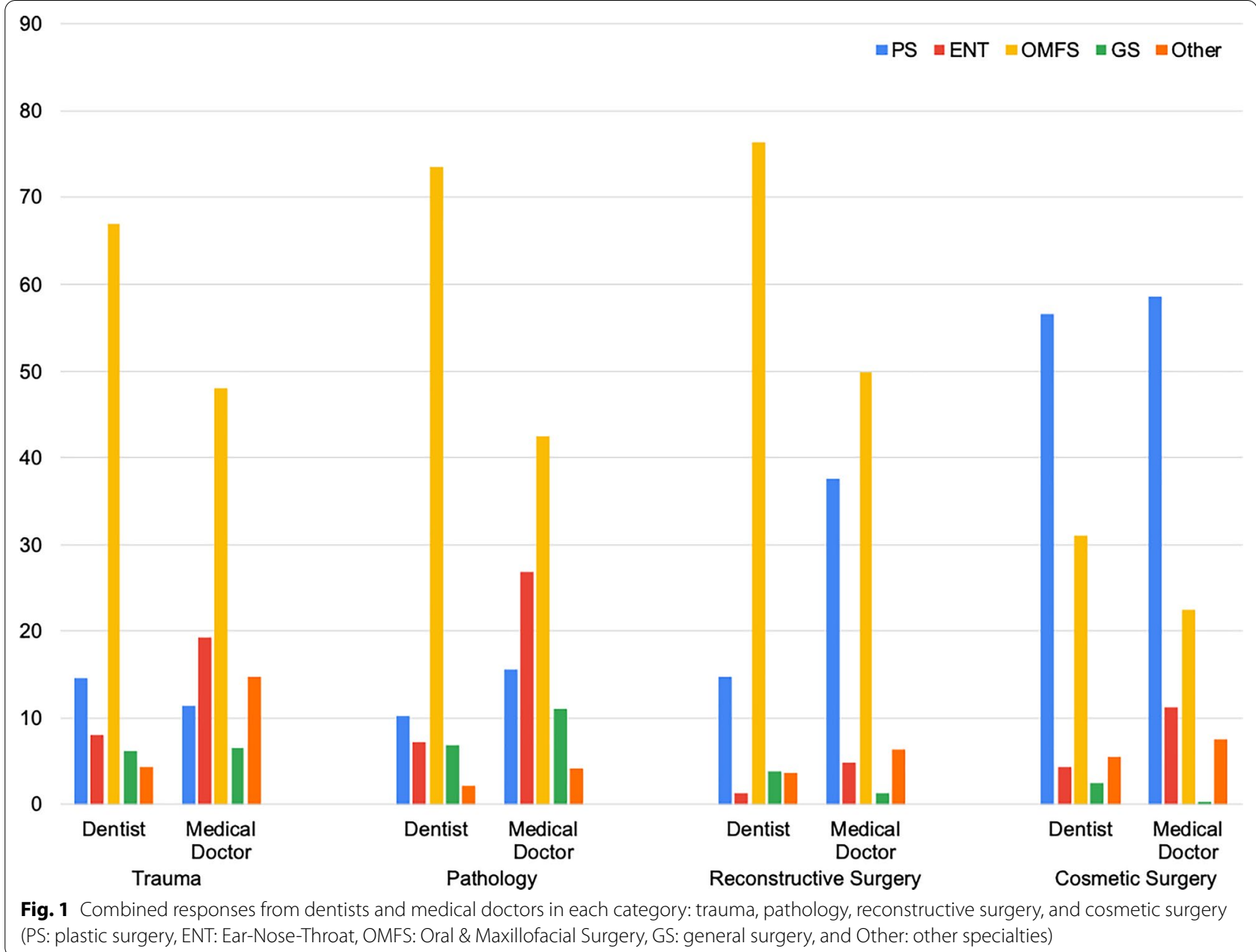

study, which stated medical doctors were less likely to refer to OMFS [7]. This may be attributed to many North American- and European-trained surgeons joining the Gulf Cooperation Council (GCC) countries workforce in recent years due to the wide implementation of the government sponsored training schemes abroad, as well as social media becoming a valid platform for patient education $[7,17]$.

Ameerally et al. mentioned that names given to specialties can create referral bias. (14) Our results demonstrated it is more likely for healthcare professionals and laypeople to refer cases of jaw, orbital, and dental trauma to OMFS. Such speculation is popular among other authors, such as Parnes who suggested a name change to OMFS altered its perceived spectrum. (15) However, it is extremely difficult to suggest a name that fully describes any given specialty [8].

Government-funded hospitals in Kuwait established broad guidelines on referrals [7]. Nasal fractures, for example, are to be referred to ENT specialists, which may explain why our results indicated ENT is the preferred specialty for nasal fracture management. We found that a significant number of dentists would also refer nasal fractures to OMFS. Dentists have firsthand experience with OMFS during undergraduate studies, and rotations and externships in OMFS service may grant dentists a firm understanding on the specialty's broad scope, on the other hand, many medical doctors are unaware of OMFS training and practice $[18,19]$.

Regarding facial lacerations, we found that dentists and medical doctors gave equal preference to PS. However, a statistically significant difference was noted between dentists (43\%) and medical doctors (19\%) referring facial lacerations to OMFS. Plastic surgeons are well known for managing cases requiring special esthetic attention, which has been reported by Alnofaie et al. [8], making it unusual that GS was the second most likely specialty referral by medical doctors for facial lacerations.

Our results indicate that while OMFS is the preferred service for any pathological case of the oral 
Table 6 General public (laypersons)

\begin{tabular}{|c|c|c|c|c|c|}
\hline Condition & Plastic surgeon & $\begin{array}{l}\text { Ear-nose- } \\
\text { throat }\end{array}$ & $\begin{array}{l}\text { Oral and maxillofacial } \\
\text { surgeon }\end{array}$ & $\begin{array}{l}\text { General } \\
\text { surgeon }\end{array}$ & Others \\
\hline Broken jaw & 0 & 2 & 92 & 0 & 6 \\
\hline Cut on the face (Laceration) & 53 & 0 & 38 & 5 & 4 \\
\hline Eye bone fracture (orbit) & 10 & 6 & 42 & 18 & 24 \\
\hline Fracture of the skull & 3 & 1 & 39 & 30 & 27 \\
\hline Nose fracture & 9 & 60 & 26 & 1 & 4 \\
\hline Trauma to the teeth & 1 & 3 & 75 & 2 & 19 \\
\hline Biopsy of a skin lesion on the face & 19 & 3 & 25 & 41 & 12 \\
\hline Biopsy of oral lesions & 4 & 19 & 45 & 14 & 18 \\
\hline Cancer of the lip & 8 & 7 & 46 & 18 & 21 \\
\hline Cancer of the mouth or tongue & 0 & 17 & 62 & 4 & 17 \\
\hline Lump in the mouth & 0 & 7 & 68 & 10 & 15 \\
\hline Lump in the neck & 5 & 31 & 4 & 38 & 22 \\
\hline Mole or lump in the face (Skin) & 58 & 1 & 20 & 14 & 7 \\
\hline Salivary gland removal (Parotid, Submandibular) & 0 & 17 & 53 & 19 & 11 \\
\hline Sinus surgery & 0 & 80 & 14 & 4 & 2 \\
\hline Child with a cleft lip & 34 & 8 & 44 & 10 & 4 \\
\hline Child with a cleft palate & 6 & 18 & 61 & 11 & 4 \\
\hline Child with a cleft lip + palate & 9 & 12 & 70 & 5 & 4 \\
\hline Dental implants & 1 & 7 & 62 & 1 & 29 \\
\hline Facial reconstruction after facial trauma & 58 & 2 & 34 & 1 & 5 \\
\hline Facial reconstruction with free flaps & 53 & 2 & 33 & 4 & 8 \\
\hline Grafting bone in the face & 20 & 4 & 62 & 8 & 6 \\
\hline Removal of wisdom teeth & 0 & 6 & 54 & 4 & 36 \\
\hline Temporomandibular Joint (TMJ) surgery & 3 & 2 & 82 & 8 & 5 \\
\hline Taking bone from rib/hip for intra-oral grafting & 13 & 3 & 58 & 17 & 9 \\
\hline Chin correction surgery & 55 & 3 & 38 & 0 & 4 \\
\hline Eyelid surgery (Blepharoplasty) & 53 & 12 & 19 & 3 & 13 \\
\hline Face lift & 92 & 1 & 2 & 0 & 5 \\
\hline Facial implants (Silicone or other alloplasts) & 79 & 4 & 12 & 0 & 5 \\
\hline Fat grafting to the face & 88 & 1 & 6 & 1 & 4 \\
\hline Hair transplant & 82 & 2 & 0 & 1 & 15 \\
\hline Injection of Botox and fillers & 90 & 2 & 2 & 0 & 6 \\
\hline Jaw deformities and discrepancy & 5 & 2 & 85 & 2 & 6 \\
\hline Laser resurfacing of facial skin & 89 & 1 & 2 & 0 & 8 \\
\hline Problem with facial appearance or asymmetry & 59 & 1 & 35 & 1 & 4 \\
\hline Rhinoplasty (Nose plastic surgery) & 72 & 19 & 4 & 1 & 4 \\
\hline
\end{tabular}

As the group contained 100 participants, cell values represent both $\mathrm{n}$ and $\%$

cavity (Table 3), medical doctors mainly referred facial pathology requiring biopsies to PS. Our consensus among health care professionals that plastic surgeons are the most competent at treating esthetic cases is consistent with previously published studies [7, 8]. Facial lesion management is within the core of OMFS specialty with most practitioners being well trained in PS, ENT, and GS. To date, OMFS is the specialty with the greatest focus on the facial region. All surgeons are held to high standards for care delivery and esthetic outcomes. Dentists are more likely to refer any given case to OMFS save skin lumps, which tended to be referred to PS.

Sinus surgeries and salivary gland removals are within the scope of OMFS and ENT. While dentists preferred OMFS referrals, doctors preferred ENT for such case management. Haron et al's study found that medical doctors would refer salivary gland pathology to GS [7]. In our study, GS was the second least preferred choice of all healthcare professionals. 


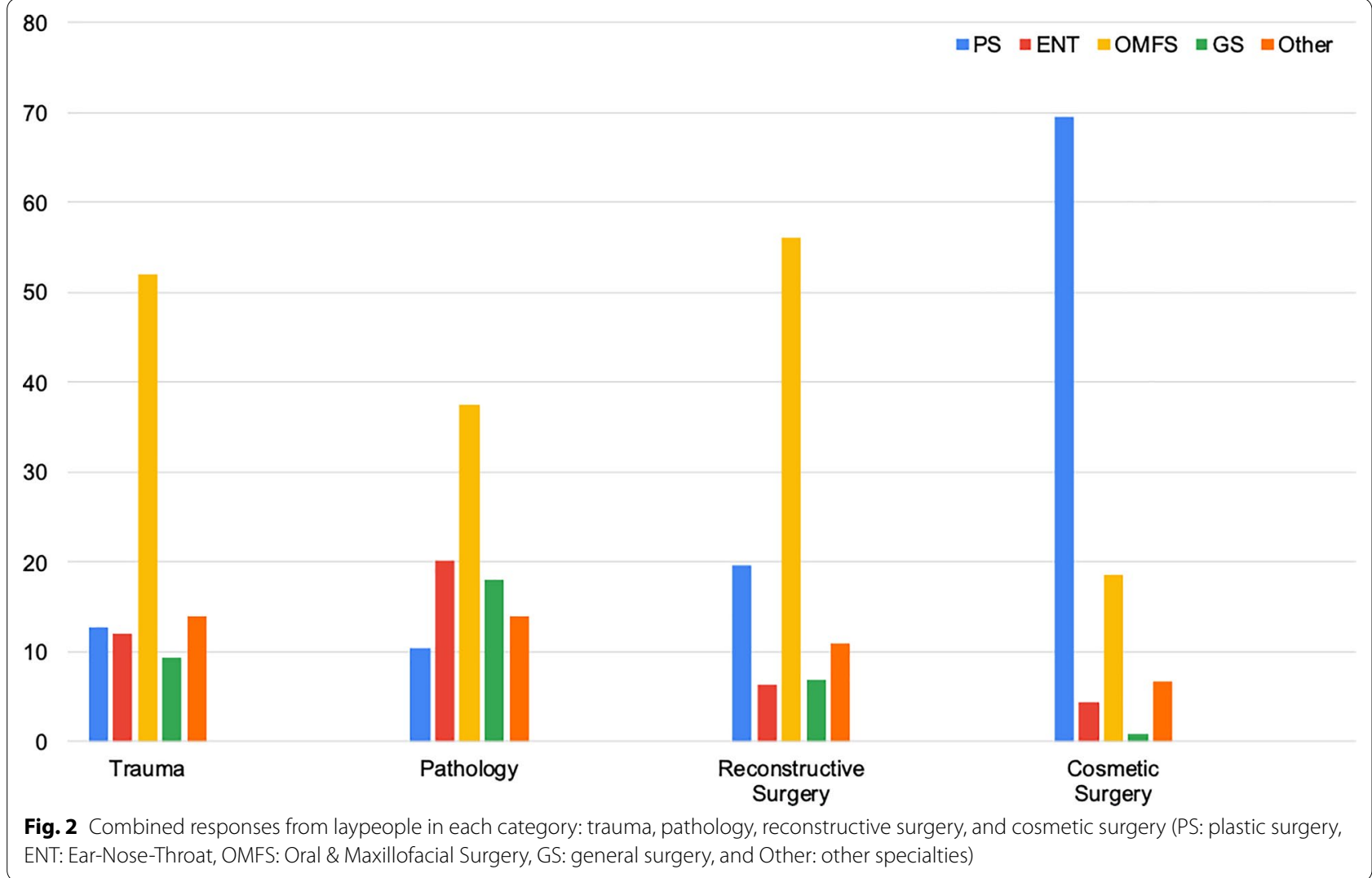

Regarding reconstructive surgery, dentists consistently referred all cases to OMFS first. However, dentists in Kuwait tend to refer any complicated head or neck region case to OMFS first [7]. Medical doctors mainly sent cleft lip and palate patients to PS. Children with cleft lips and palates require a team of healthcare professionals including orthodontists, pediatric physicians and dentists. The tendency of professionals to refer cleft lip and palate cases to PS could be attributed to the fact that the operatory segment of the cleft team governmental hospital established is consisted of plastic surgeons. Management of temporomandibular joints were mainly referred to OMFS by our participants, which was consistent with other published results $[8,12]$. Wisdom teeth extraction and dental implants were mainly sent to OMFS. A significant number of dentists and medical doctors chose to send such cases to professionals marked as "others", such periodontists and general dentists trained to manage minor oral surgical procedures (Table 4). Undoubtedly, their competence in such surgical intervention will reduce the burden on busy OMFS specialists in Kuwait.

For cosmetic surgery, all plastic facial procedures (except for chin corrections) were most likely to be sent to PS. Healthcare professionals prefer PS for Botox injections and hair transplants. Numerous specialties offer similar procedures, including dermatology, but the predominant worldwide perception that PS is a specialty dedicated to esthetics, with similar results found in other studies $[12,20]$.

Almost all facial operations should have acceptable esthetic results, rendering them cosmetic [21]. It is worrisome that healthcare professionals would refer most of such patients a specific surgical specialty, even OMFS. Specialty overlap requires consideration and referrals should be distributed equally with emphasis on any given surgeon's expertise and skills. OMFS will evolve hugely based on experience, thus a proper referral system that considers its overlap and the training of different departments can be counted as a good investment in healthcare. Rhinoplasties are controversial as far as which specialty should offer care with PS and ENT being the top choices.

Laypeople preferred OMFS for all traumatic cases involving the face, except for nasal fractures where ENT scored higher. The Arabic name for OMFS translates literally to "jaw and facial surgery". It seems reasonable that descriptive name and nomenclature play a key role in choosing departments. Generally, laypeople are more likely to view OMFS surgeons as performing procedures involving the head and neck region, with the only significant exception being esthetic procedures, 
Table 7 Perception of when to consult an oral and maxillofacial surgeon for various conditions

\begin{tabular}{|c|c|c|c|c|}
\hline Condition & Dentist & Medical doctor & $P^{*}$ & Laypeople \\
\hline \multicolumn{5}{|l|}{ Trauma } \\
\hline Broken jaw & 99 & 100 & 1.000 & 92 \\
\hline Cut on the face (Laceration) & 43 & 19 & $<0.001$ & 38 \\
\hline Eye bone fracture (orbit) & 83 & 67 & 0.009 & 42 \\
\hline Fracture of the skull & 68 & 23 & $<0.001$ & 39 \\
\hline Nose fracture & 37 & 4 & $<0.001$ & 26 \\
\hline Trauma to the teeth & 72 & 75 & 0.631 & 75 \\
\hline \multicolumn{5}{|l|}{ Pathology } \\
\hline Biopsy of a skin lesion on the face & 53 & 19 & $<0.001$ & 25 \\
\hline Biopsy of oral lesions & 87 & 80 & 0.182 & 45 \\
\hline Cancer of the lip & 87 & 55 & $<0.001$ & 46 \\
\hline Cancer of the mouth or tongue & 97 & 84 & 0.003 & 62 \\
\hline Lump in the mouth & 94 & 81 & 0.005 & 68 \\
\hline Lump in the neck & 63 & 7 & $<0.001$ & 4 \\
\hline Mole or lump in the face (Skin) & 39 & 18 & 0.001 & 20 \\
\hline Salivary gland removal (Parotid, Submandibular) & 90 & 31 & $<0.001$ & 53 \\
\hline Sinus surgery & 51 & 7 & $<0.001$ & 14 \\
\hline \multicolumn{5}{|l|}{ Reconstructive surgery } \\
\hline Child with a cleft lip & 72 & 31 & $<0.001$ & 44 \\
\hline Child with a cleft palate & 88 & 30 & $<0.001$ & 61 \\
\hline Child with a cleft lip + palate & 86 & 31 & $<0.001$ & 70 \\
\hline Dental implants & 77 & 80 & 0.606 & 62 \\
\hline Facial reconstruction after facial trauma & 69 & 48 & 0.003 & 34 \\
\hline Facial reconstruction with free flaps & 47 & 28 & 0.006 & 33 \\
\hline Grafting bone in the face & 75 & 44 & $<0.001$ & 62 \\
\hline Removal of wisdom teeth & 87 & 66 & $<0.001$ & 54 \\
\hline Temporomandibular Joint (TMJ) surgery & 95 & 90 & 0.179 & 82 \\
\hline Taking bone from rib/hip for intra-oral grafting & 67 & 51 & 0.021 & 58 \\
\hline \multicolumn{5}{|l|}{ Cosmetic surgery } \\
\hline Chin correction surgery & 73 & 56 & 0.012 & 38 \\
\hline Eyelid Surgery (Blepharoplasty) & 28 & 4 & $<0.001$ & 19 \\
\hline Face lift & 24 & 9 & 0.004 & 2 \\
\hline Facial implants (Silicone or other alloplasts) & 36 & 21 & 0.019 & 12 \\
\hline Fat grafting to the face & 19 & 12 & 0.171 & 6 \\
\hline Hair transplant & 3 & 0 & 0.246 & 0 \\
\hline Injection of Botox and fillers & 11 & 0 & 0.001 & 2 \\
\hline Jaw deformities and discrepancy & 93 & 92 & 0.788 & 85 \\
\hline Laser resurfacing of facial skin & 6 & 2 & 0.279 & 2 \\
\hline Problem with facial appearance or asymmetry & 44 & 43 & 0.887 & 35 \\
\hline Rhinoplasty (nose plastic surgery) & 4 & 9 & 0.251 & 4 \\
\hline
\end{tabular}

* Statistical comparisons were performed between dentists and medical doctors only. As each group contained 100 participants, cell values represent both $\mathrm{n}$ and $\%$

for which they prefer PS. This public perception of PS is longstanding and affected by popular culture and social media. A major limitation in our study is that the sample size $(n=100)$ was small to draw a broader conclusion on a complex and diverse healthcare system in Kuwait. Given the dynamic nature of the healthcare system in Kuwait with constant influx of healthcare professionals from various global systems and training schemes, the results can show significant variations within short time frames, as seen in this study with regard to the previous views recorded in 2013. 


\section{Conclusions}

In conclusion, we observed an acceptable perception and awareness of both medical doctors and dentists towards OMFS. However, physicians seem less aware than dentists and both populations perceive cosmetic procedures as manageable by PS. We suggest developing a database of surgeons with their demonstrable surgical interventions. This database will aid referrals, since cases are sent to surgeons with the most experience, interest, or willingness to manage them. There is a need to increase awareness among all healthcare providers and the general public regarding the scope of clinical practice for the specialty of Oral and Maxillofacial Surgery, and especially towards cosmetic surgery procedures. Improving knowledge and awareness towards OMFS specialty will help in further advancing the frontiers of this specialty, and ultimately helping in delivering better care to the public.

\section{Abbreviations}

OMFS: Oral and maxillofacial surgery; ENT: Ear, nose, and throat; PS: Plastic surgery; GS: General surgery.

\section{Acknowledgements}

Not applicable.

\section{Authors' contributions}

MK and MA conceived and designed the study. MK collected the data work on the acquisition and analyses. MK and AA interpret the data. MK, AA and MA have drafted the work or substantively revised it. All authors read and approved the final manuscript.

\section{Funding}

No funding was used for this study.

\section{Availability of data and materials}

The datasets used and analyzed in the study are available from the corresponding author on reasonable request.

\section{Ethics approval and consent to participate}

The Ethical Committee at Kuwait University approved the study, in accordance with the Helsinki Declaration. All participants gave written consent and filled out the questionnaire voluntarily, and their responses were kept anonymous.

\section{Consent for publication}

Not applicable.

\section{Competing interests}

The authors declare that they have no conflicts of interest and nothing to disclose.

\section{Author details}

${ }^{1}$ Department of Surgical Sciences, Faculty of Dentistry, Health Sciences Center, Kuwait University, Safat, Kuwait. ${ }^{2}$ Kuwait Dental Administration, Ministry of Health, Safat, Kuwait.

Received: 13 August 2020 Accepted: 14 January 2021

Published online: 26 January 2021
2. Vadepally AK, Sinha R. What surgical education the speciality offers? perception of role of oral and maxillofacial surgery by 1200 healthcare professionals, students and the general public in Hyderabad, India. J Maxillofac Oral Surg. 2018;17(2):182-7.

3. Lababidi E, Breik O, Subramaniam S. Perceptions of oral and maxillofacial surgery amongst Australian medical general practitioners. J Oral Maxillofac Surg Med Pathol. 2018;30(3):229-32.

4. Mohanty R, Singh V. An analysis of approach toward oral and maxillofacial surgery: a survey of 1800 health-care specialists, students, and general people in Odisha, India. Natl J Maxillofac Surg. 2019;10(1):68.

5. Ali FM, Al-Iryani GM, Namis SM, Hezam AA, Swaid SA, Alomar AE. Knowledge and awareness of medical practitioners of Jazan city towards oral and maxillofacial surgery as a specialty. Open Access Macedonian J Med Sci. 2018;6(3):588.

6. Shah N, Patel N, Mahajan A, Shah R. Knowledge, attitude and awareness of speciality of oral and maxillofacial surgery amongst medical consultants of Vadodara District in Gujarat State. J Maxillofac Oral Surg. 2015;14(1):51-6.

7. Haron IM, Sabti MY, Andersson L, Sharma PN. Perception of oral and maxillofacial surgery by medical and dental health care professionals in Kuwait. J Oral Maxillofac Surg Med Pathol. 2013;25(1):5-11.

8. Alnofaie H, Alchawaf B, AlKindi M. Knowledge, awareness, and perception of oral and maxillofacial surgery among the public and professionals in Saudi Arabia: a cross-sectional study. Int J Oral Maxillofac Surg. 2019:48(12):1597-603.

9. Ghobashi MM, El-Ragehy HAG, Ibrahim HM, Al-Doseri FA. Assessment of patient safety culture in primary health care settings in Kuwait. Epidemiol Biostat Public Health. 2014;11:3.

10. Ahmed Z, Saada M, Jones AM, Al-Hamid AM. Medical errors: healthcare professionals' perspective at a tertiary hospital in Kuwait. PLoS ONE. 2019;14(5):e0217023.

11. Ali H, Ibrahem SZ, Al Mudaf B, Al Fadalah T, Jamal D, El-Jardali F. Baseline assessment of patient safety culture in public hospitals in Kuwait. BMC Health Services Res. 2018;18(1):158.

12. Rocha N, Laureano Filho J, Silva E, Almeida R. Perception of oral maxillofacial surgery by health-care professionals. Int J Oral Maxillofac Surg. 2008;37(1):41-6.

13. Rocha N, Saturnino E, Martins T, Laureano Filho J, Almeida R. Perception of oral and maxillofacial surgery by Brazilian healthcare professionals: what has changed in ten years? Int J Oral Maxillofac Surg. 2017;46(8):1062-9.

14. Jensen CB. The continuum of health professions. Integr Med Clin J. 2015;14(3):48

15. Barua B, Esmail N. Waiting your turn: wait times for health care in Canada, 2013 report. Fraser Institute, Studies in Health Policy. 2013.

16. Greenwood-Lee J, Jewett L, Woodhouse L, Marshall DA. A categorisation of problems and solutions to improve patient referrals from primary to specialty care. BMC Health Serv Res. 2018;18(1):986.

17. Alhuwail $D$, Abdulsalam $Y$. Assessing electronic health literacy in the state of Kuwait: survey of internet users from an Arab state. J Med Internet Res. 2019;21(5):e11174.

18. Kielty P, O'Connor B, Cotter C, Goodson A, Payne K, Tahim A. Medical students' understanding of oral and maxillofacial surgery: an Irish perspective. Br J Oral Maxillofac Surg. 2017;55(4):371-7.

19. Mahalingam S, Kalia P, Mugilan S. Oral and maxillofacial surgery in medical schools in the United Kingdom. Br J Oral Maxillofac Surg. 2015;53(3):295-7.

20. Hunter MJ, Rubeiz T, Rose L. Recognition of the scope of oral and maxillofacial surgery by the public and health care professionals. J Oral Maxillofac Surg. 1996;54(10):1227-32.

21. Mommaerts MY. The surgical art of facial makeover. Orthoface R \& D GCV. 2013.

\section{Publisher's Note}

Springer Nature remains neutral with regard to jurisdictional claims in published maps and institutional affiliations.

\section{References}

1. Harris K, Jefferies C. A multi-site cross-sectional survey exploring medical undergraduate knowledge of oral and maxillofacial surgery. J Maxillofac Oral Surg. 2019;18(4):623-7. 